\title{
A teoria da forma de Kandinsky: uma compreensão artística e subjetiva de elementos geométricos
}

Kandinsky's theory of form: an artistic and subjective understanding of geometric elements

João Carlos Pereira de Moraes $^{1}$

\section{Resumo}

O presente estudo emerge do encontro do seu pesquisador, um professor de matemática, com a obra Ponto e Linha sobre o Plano de Wassili Kandinsky (1866-1944). Deste encontro emerge o objetivo de analisar a relação de Kandinsky, em sua Teoria da Forma, com o pensamento geométrico para a construção da arte abstracionista. Para tanto, o pesquisador realiza uma leitura crítica da obra do artista, apontando os olhares e significâncias subjetivas dadas para os elementos geométricos ponto, linha e plano. Como resultado, nota-se que a obra do artista em questão ressoa, a partir de tais elementos, muito dos aspectos históricos e culturais do início do século XX, tanto os presentes na ciência quanto no ideário da sociedade.

Palavras chave: Teoria da Forma; Elementos Geométricos; Matemática; Arte.

\section{Abstract}

The present study emerges from the meeting of his researcher, a mathematics teacher, with the work Ponto e Linha on the Plan by Wassili Kandinsky (1926). This meeting insists on the objective of analyzing Kandinsky's relationship, in his Theory of Form, with geometric thinking for the construction of abstractionist art. For this, the researcher performs a critical reading of the artist's work, pointing out the looks and subjective meanings given to the geometric elements point, line and plane. As a result, it is noted that the work of the artist in question resonates, from such elements, much of the historical and cultural aspects of the beginning of the 20th century, both present in science and in the ideas of society.

Keywords: Theory of Form; Geometric Elements; Mathematics; Art.

\footnotetext{
${ }^{1}$ Universidade Federal do Pampa | joaomoraes@unipampa.edu.br
} 


\title{
Introdução
}

\begin{abstract}
A primeira coisa que nos chama a atenção é, sem dúvida, a modéstia do título adotado para esta obra: Ponto e Linha sobre o plano, contribuição à análise dos elementos da pintura. No entanto, acolhemos um livro inteiro consagrado a um tema de aparência tão insignificante com uma glutonice especial: à simples leitura do título, já ouvimos chiar a pena, vemos deslizar o pincel ou esfregar o lápis e carvão, porque a folha está diante de nossos olhos, a folha, a tela ou o painel, o plano em todo o caso, esse plano original ou esse plano básico (Grundflãche) pronto para receber o choque do ponto ou a carícia da linha (SERS, 2005, p. XII, grifos nossos).
\end{abstract}

No excerto acima, trazemos à tona as palavras de Sers (2005) sobre o livro Ponto e Linha sobre o Plano de Wassaly Kandinsky (1886-1944), artista plástico de origem russa, professor da Bauhaus e introdutor da abstração no campo das artes visuais. Talvez o romantismo com o qual o crítico apresenta a obra nos dê uma compreensão de que o estudo está focado mais numa fazer filosófico da arte, do que numa perspectiva prática da profissão pintor-artista. Eis um engano, Kandinsky quis propagar uma teoria da forma, uma teoria para dar conta ao movimento abstracionista, do qual ele foi um dos fundadores (FORTUNA, 2006).

No entanto, não posso negar a questão subjetiva envolvida na obra de Kandinsky. A perspectiva do artista seria a construção de uma geometria que pudesse dar emoção ao quadro, sendo capaz de criar impactos. Nesse sentido, Kandinsky vê em elementos básicos da construção do espaço matemático (ponto, linha e plano) uma possibilidade de retirar a descrição direta do que é visto e criar uma nova forma de olhar a realidade. Um real que acontece pelos sentimentos.

Dito isto, a intenção deste texto é analisar a relação de Kandinsky, em sua Teoria da Forma, com o pensamento geométrico para a construção da arte abstracionista. Com esta ideia, seguiremos os referidos pontos para apresentar o estudo: o debate sobre a base filosófica da teoria de Kandinsky, elaborando intersecções entre o relato do artista e o pensamento científico ao início do século XX. Feito isso, ingressamos nos elementos ${ }^{2}$ básicos do livro: o ponto, a linha e o plano, elencando as sistematizações feitas pelo pintor. E, por fim, expomos as possíveis ressonâncias interiores que elas podem instaurar conforme o pensamento do artista.

\section{Três questões científicas e uma teoria da forma}

$\mathrm{Na}$ introdução de Ponto e Linha sobre o Plano, Kandinsky prepara o leitor a fim de que ele possa compreender sua "ciência da forma" (KANDINSKY, 2005), citando finalidades, relevância histórica, caminhos de pesquisa, entre outros princípios que se assemelham a um estudo investigativo em campos como, por exemplo, o das ciências exatas. Tais afinidades nos levam a duas possíveis inferências: (1) as semelhanças presentes no livro do artista com

\footnotetext{
${ }^{2}$ Conforme Kandinsky (2005, p. 25), "a noção de elemento pode ser interpretada de duas maneiras: como noção exterior ou interior. Exteriormente, toda forma gráfica ou pictórica é um elemento. Interiormente, não é a forma, mas sua tensão viva intrínseca que constitui o elemento".
} 
o campo das ciências exatas são meras coincidências ou, talvez, (2) sejam indícios de convergências entre o pensamento artístico do pintor com as questões científicas ao início do século XX. Pautar-nos-emos na segunda opção, relatando, a seguir, as intersecções entre a arte e a ciência do período que construímos.

Antes, é preciso retroceder um pouco, mais precisamente até o século XIX, para começar a debater o assunto. Para isso, nos embasamos na análise arquitetada por Crary (2012), em Técnicas do Observador. Segundo o autor, ocorreram à época diversas mudanças de ordem filosófica e epistemológica que possibilitaram à cultura ocidental uma abertura para caminhos mais subjetivos da visão. O regime clássico de visualidade havia sido destituído de sua hegemonia para ceder espaço a modelos mais subjetivos do ver. 0 olhar do observador tornava-se dependente do funcionamento fisiológico de seu corpo, perdendo o status de perfeição e objetividade instaurado no Renascimento. Ou seja, o século XIX é marcado pela visão que "deixa de estar subordinada a uma imagem exterior do verdadeiro ou do certo. Não é mais o olho que alardeia um 'mundo real'" (CRARY, 2012, p. 135).

Embora os relatos de Crary (2012) tragam palavras-chaves como olhar, observador, visão e visualidade, associadas, geralmente, às artes, seu estudo condiz antes com uma genealogia ${ }^{3}$ das técnicas para observar do que com um livro de história da arte, já que o autor trata, mediante certos aparatos tecnológicos, das condições de possibilidade para a produção dos saberes do Renascimento até o século XIX. Isso acarreta que, imbricados ao estudo, não estão somente os saberes artísticos, mas também aqueles produzidos no campo científico.

Em Kandinsky, essa "visão mais subjetiva" se traduz na negação da técnica da perspectiva e na busca de outra estrutura artístico-matemática às suas obras, uma que pudesse dar maior visibilidade ao interior humano:

(...) deve-se admitir, deve-se considerar como boa (como artística) toda forma que constitui uma expressão exterior do conteúdo interior. Caso contrário, já não é ao espírito livre (o raio branco) que se serve, mas a barreira petrificada (a mão negra). (...) de modo geral, não é a forma (matéria), que é elemento essencial, mas o conteúdo (espírito) (KANDINSKY, 1991b, p. 120).

Para pensar as ressonâncias desse novo estatuto do observador na ciência, somos provocados por Boaventura de Sousa Santos (1996). O sociólogo da ciência demonstra que ingressamos, desde o final do século XIX, numa "crise da ciência", em que, devido ao aprofundamento do conhecimento na ciência moderna ${ }^{4}$, foi possível identificar limites,

\footnotetext{
${ }^{3}$ Pautado nas leituras de Foucault, Castro (2009) considera a genealogia uma análise que se concentra nas séries de formação efetiva dos discursos, apreendendo os em seu poder de afirmação. Conforme o autor, a genealogia coloca em funcionamento três regras metodológicas: "o princípio da descontinuidade (tratar os discursos como práticas descontínuas, sem supor que sob os discursos efetivamente pronunciados existe outro discurso, ilimitado, silencioso e contínuo, que é reprimido ou censurado); o princípio da especificidade (considerar os discursos como uma violência que exercemos sobre as coisas, não há providência pré-discursiva); o princípio da exterioridade (não ir ao núcleo interior e escondido do discurso, o pensamento, a significação; dirigir-se às suas condições externas de surgimento)" (CASTRO, 2009, p. 185).

${ }^{4}$ Segundo Sousa Santos (1996), a ciência moderna estrutura-se a partir da revolução científica do século XVI. Para nós, sua característica mais interessante está na permanente autodefesa que visava à proteção, "por via de
} 
insuficiências estruturais e fragilidades do próprio campo (SOUSA SANTOS, 1996). Ele elenca quatro condições teóricas para a crise, das quais nos apropriamos de três ${ }^{5}$ para debater a obra de Kandinsky e o pensamento de Crary (2012).

A primeira delas é a relatividade da simultaneidade. Nessa teoria, Einstein diferencia a simultaneidade dos acontecimentos ocorridos em lugares próximos daqueles sucedidos em lugares separados por distâncias astronômicas. Para trabalhar com a ordem temporal desses últimos, o físico vê-se numa contradição: para "determinar a simultaneidade dos acontecimentos distantes é necessário conhecer a velocidade; mas para medir a velocidade é necessário conhecer a simultaneidade dos acontecimentos" (SOUZA SANTOS, 1996, p. 8). A conclusão de Einstein foi a seguinte: não existe uma simultaneidade universal dos acontecimentos e sim simultaneidades relativas. Desta forma, tanto o tempo quanto o espaço são pensados por Newton como absolutos que inexistem. A única afirmação passível de ser feita é que eles são, também, relativos.

Conforme Barbosa (1995), junto com a questão científica da relatividade, instaurou-se um pensamento filosófico relativo. Pensadores racionalistas e realistas entraram em choque e a noção de que todos os saberes são fixados por princípios absolutos foi abalada. O mundo absoluto do qual a humanidade buscava criar representações desmoronou, emergindo, em seu lugar, um mundo relativo capaz apenas de ser analisado por verificações (BARBOSA, 1995). A natureza, até então de representação una, encontrava, através da ciência, novas possibilidades para ser apreendida.

Semelhante à ciência, no abstracionismo de Kandinsky, a forma possui uma natureza múltipla, já que a inserção da alma do observador na pintura abre-a para a diversidade de interpretações:

Um acontecimento científico removeu um dos obstáculos mais importantes nesse caminho [de produção do abstracionismo]. Foi a divisão do átomo ${ }^{6}$. A desintegração do átomo era a mesma coisa, em minha alma, que a desintegração do mundo inteiro. As paredes mais espessas desabavam subitamente. Tudo se tornava precário, instável, mole. Não me espantaria ver uma pedra fundir-se no ar na minha frente e tornar-se invisível. A ciência parecia-me aniquilada: suas bases mais sólidas não passavam de um engodo, de um erro dos cientistas, que não construíam seu edifício divino pedra por pedra, com mão tranqüila, sob uma luz transfigurada, mas tateavam na escuridão, ao acaso, à procura de verdades, e em sua cegueira tomavam um objeto por outro (KANDINSKY, 1991a, p. 79)

fronteiras ostensivas e ostensivamente policiadas, de duas formas de conhecimento não científico (e, portanto, irracional) potencialmente perturbadoras e intrusas: o senso comum e as chamadas humanidades ou estudos humanísticos (em que se incluíram, entre outros, os estudos históricos, filológicos, jurídicos, literários, filosóficos e teológicos)" (SOUSA SANTOS, 1996, p. 3).

${ }^{5}$ A condição de Sousa Santos (1996) não utilizada por nós são os avanços nos domínios da microfísica, da química e da biologia, iniciados a partir da década de 1970. Ou seja, posteriores ao trabalho de Kandinsky.

${ }^{6}$ Para alguns historiadores de arte, essa citação de Kandinsky refere-se à descoberta da Radioatividade Natural (a decomposição do átomo de Urânio) por Henri Becquerel, para outros, Kandinsky fez alusão às descobertas do Rádio (elemento químico radioativo) pelo casal Pierre e Marie Curie (SCHIMIDT, 1999). 
A partir da renúncia da matéria como fundamento da realidade, a pintura kandinskiana busca um afastamento da representação dos objetos. Segundo Sers (2005, p. XIV), o pintor considera o objeto "nocivo à pintura, mas ao mesmo tempo é preciso que se constitua a lógica pictórica de uma forma sem objeto", que seja substituta da técnica da perspectiva.

Assim como a ciência, a pintura para Kandinsky reivindica o poder de descobrir e descrever o universo microscópico e o macroscópico com suas leis matemáticas e formas abstratas, por meio de uma analogia com o sensível objetivado, não na sua representação conceitual, mas sim, na linguagem formal da pintura abstrata (MENON, 2014, p. 134).

Mesmo não sendo mais possível considerar a natureza em si como um objeto de pesquisa, a necessidade de discuti-la e manipulá-la engendrou um novo caminho de estudo, agora pautado em seus conceitos organizadores. Conforme Silva (2010), a partir da crise da ciência moderna, o real que confere status de válido ao conhecimento são as "relações naturais elementares", as chamadas "leis da natureza", já que a própria matéria molda-se e está condicionada a elas. Isto é, conhecer tornou-se um ato de traduzir fenômenos e objetos de estudo em conceitos lógico-matemáticos abstratos. Tanto Einstein e Heisenberg prescreviam uma ciência pautada estritamente nessas bases. Já na arte, em sua Teoria da Forma, Kandinsky concebia, como necessidade, a elaboração de uma estrutura lógica para atingir a ressonância interior na construção da pintura abstracionista.

Desta forma, passamos à terceira condição científica, o rigor matemático. Juntamente com a mecânica quântica e com a relatividade, a ciência do século XX elevou-se ao patamar do pensamento puro, realizável somente por princípios da lógica e da matemática. Até mesmo a experimentação, característica essencial da ciência moderna, foi substituída por essa nova forma de pensar, uma vez que os fenômenos e escalas da natureza da nova ciência não eram passíveis de observação. Segundo Silva (2010), o pensamento do período era que

a natureza, o mundo material, emerge segundo uma ordem, segundo relações, simetrias, enfim, segundo leis, sem as quais o mundo material sequer poderia existir, e que tais leis que Ihes são imanentes, são leis abstratas, sem materialidade. Não se pode "pesar", observar uma lei, ela mesma, mas somente seus efeitos (SILVA, 2010, pp. 34-35).

De modo análogo, Kandinsky, com a Teoria das Formas, elabora um pensamento matemático para a composição pictórica, em que o universo material do quadro emerge de leis abstratas, imateriais. Essas não podem ser "pesadas" e observadas, mas podemos sentir os seus efeitos, as ressonâncias interiores que instauram no observador. A seguir, discutiremos os elementos dessa construção.

\section{Um ponto...}

O ponto é a origem, a concisão absoluta, o uno bem definido, o início de todos os outros elementos. Na Teoria das Formas, de Kandinsky, significa um conceito primitivo, uma noção intuitiva dada pela experiência cotidiana. É o elo entre o interior e o exterior: 


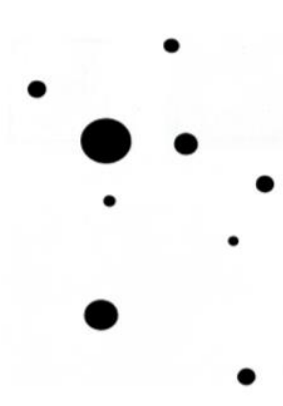

Figura 1: Prancha 3. Fonte: Kandinsky (2005)

(...) um ser invisível. Portanto, definido como imaterial. Do ponto de vista material, o ponto é igual a Zero. Mas esse Zero esconde diferentes propriedades "humanas". De acordo com nossa concepção, esse Zero - o ponto geométrico - evoca a concisão absoluta, isto é, a maior reserva, que no entanto fala (KANDINSKY, 2005, p. 17).

Para o artista, o ponto geométrico é, antes de tudo, uma expressão do silêncio, nascida na escrita. Algo que interrompe. Um elemento de uso tradicional que se tornou hábito, capaz, em sua utilização rotineira, de impelir o potencial de expressão interior e de sensibilidade viva do homem. Foi contra esse ponto apático instaurado pelo dia a dia que Kandinsky formulou sua arte. O objetivo era construir pontos que ressoassem, vibrassem e produzissem crises no interior do sujeito, insuflando de vida o indivíduo letargo. Com isso, o pintor almejava educar aquele que olha, produzir observadores de

olho aberto e ouvido atento [que] transformam as mais íntimas sensaç̃̃es em acontecimentos importantes. (...) explorador[es que] descobre[m] novos países desconhecidos, descobertas no "cotidiano", e no entorno, ordinariamente mudo. Os signos mortos se tornam símbolos vivos, e o que estava morto revive (KANDINSKY, 2005, pp. 18-19).

Enquanto na escrita o ponto pertence a uma condição prático-utilitária imposta pela sociedade, na arte abstrata, ele é repleto de necessidade interior. A sonoridade do ponto artístico não aponta ressonâncias homogêneas e absolutas nos sujeitos que o vê, pois, se assim fosse, pregar-se-ia uma nova proposta utilitarista do olhar, com o intuito de domesticar a alma do observador. Sua visualização é sempre uma experiência relativa, complexa e singular.

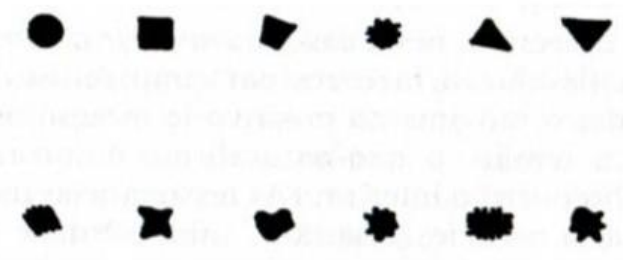

Figura 2: exemplo de formas de pontos. Fonte: Kandinsky (2005)

Segundo Kandinsky (2005), por ser relativo, esse elemento pode sofrer alterações em sua dimensão, forma e localização no espaço. E, como causa primária de tais variações, o artista aponta as sonoridades interiores e a relação limítrofe entre ponto e plano podemos conceber o ponto como um mínimo encontro material entre o lápis e o papel ou, até mesmo, o plano inteiro. 

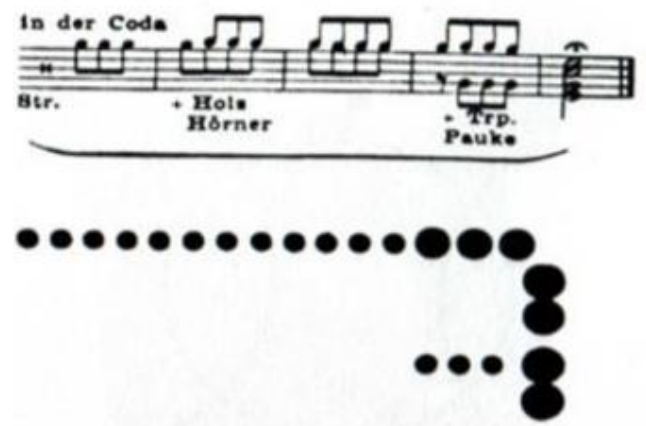

Figura 3: tempo e espaço e m música e pintura. Fonte: Kandinsky (2005)

Embora possa ser múltiplo, com contornos e aparências distintas, e significados interiores diferentes, sua forma abstrata ideal é o arredondado. O ponto marca, ainda, um espaço/lugar fixo no plano e o cessar do tempo na obra de arte. Assim como na ciência, na Teoria da Forma de Kandinsky, tempo e espaço não são separáveis, mas interdependentes, embora a ação do pintor sobre um deles acarrete, necessariamente, mudanças no outro.

\section{Uma linha...}

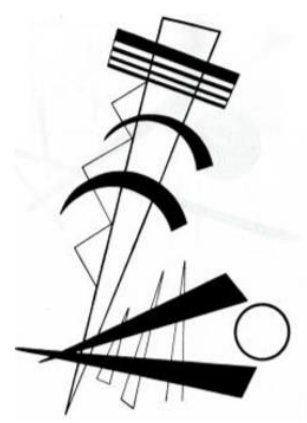

Figura 4: Prancha 8. Fonte: Kandinsky (2005)

A linha é filha do ponto e, ao mesmo tempo, sua maior opositora. Nasce da movimentação ${ }^{7}$ dele sobre a superfície, sendo capaz de romper com a inércia que a natureza impôs ao plano. Por esse aspecto, configura-se como oponente do ponto. Enquanto ela se vincula ao movimento, o outro prescreve a letargia. Assim, na Teoria de Kandinsky, as formas lineares não seriam elementos primários, mas secundários, derivados do ponto:

A linha geométrica é um ser invisível. É o rastro do ponto em movimento, logo seu produto. Ela nasce do movimento - e isso pela aniquilação da imobilidade suprema do ponto. Produz-se aqui o salto do estático para o dinâmico (KANDINSKY, 2005, p. 49).

${ }^{7}$ Conforme Kandinsky (2005), o movimento é composto por tensão e direção. A primeira seria a força viva do elemento, e a segunda, o deslocamento. O ponto tem tensão; a linha, tensão e direção. 
Ou seja, a linha consiste no ponto móvel, transformado pela ação de forças externas. Forças essas que nem sempre são iguais e que, na sua variedade, definem tipologias diversas para as linhas construídas. Para categorizar tal pluralidade, Kandinsky reduz as linhas possíveis em dois casos, conforme a tabela abaixo:

\begin{tabular}{|l|l|l|}
\hline \multirow{2}{*}{ Ação de uma única força } & Ação de duas forças \\
\cline { 2 - 3 } & $\begin{array}{l}\text { Efeito alternado das duas } \\
\text { forças, único ou repetido }\end{array}$ & $\begin{array}{l}\text { Efeito simultâneo das duas } \\
\text { forças }\end{array}$ \\
\hline Linha Reta: & Linha Reta Quebrada: & Linha Curva: \\
(1) Horizontal; & (1) Angular; & (1) Curva simples; \\
(2) Vertical; & (2) Complicada. & \\
(3) Diagonal; & & \\
(4) Livres; & \\
\hline Linhas Combinadas: & \\
(1) Geométrica; & \\
(2) Mista & \\
(3) Livre & \\
\hline
\end{tabular}

Tabela 1: Separação de Linhas pela Ação de forças. Fonte: a pesquisa

\section{Linha Reta}

O grupo das retas é o primeiro descrito por Kandinsky (2005). Ocorre quando uma força faz o ponto mover-se ao infinito e em apenas uma direção, o que condiciona a reta a ser um elemento unidimensional e a "forma mais concisa das infinitas possibilidades de movimento" (KANDINSKY, 2005, p. 49). Porém, para o pintor, nem toda linha reta é igual. Baseado nos movimentos de tensão e de direção exercidos sobre o ponto de origem, ele as separa em três grupos:

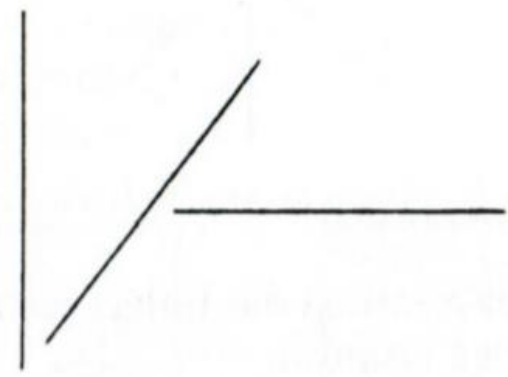

Figura 5: Arquétipos de linhas retas. Fonte: Kandinsky (2005)

(1) Linhas Retas Horizontais: a mais simples das linhas retas. Confunde-se com a superfície em que o homem deita, move e se apoia, assemelhando-se ao plano de ações dos sujeitos. Para Kandinsky, esse tipo de linha possui uma natureza que corresponde ao silêncio-calmaria e à cor preta. Representa a "forma mais concisa de todas as possibilidades de movimentos frios" (Idem, p. 51).

(2) Linhas Retas Verticais: linha parcialmente oposta à linha horizontal, com a qual forma o ângulo reto. Kandinsky associa-a ao silêncio-estagnação e à cor branca, bem como à sonoridade mínima das formas, considerando-a o elemento que ressoa uma tendência ao infinito. Representa a "forma mais concisa das infinitas possibilidades de movimentos quentes" (Idem, ibidem). 
(3) Linhas Retas Diagonais: considerada o entremeio equidistante da linha vertical com a horizontal, com as quais forma dois ângulos iguais de $45^{\circ}$. Prescreve o equilíbrio exato, refletindo tanto a sonoridade interna do frio quanto do quente. É associada ao misto de branco e preto, capaz de produzir a cor cinza. Representa a "forma mais concisa das infinitas possibilidades de movimentos frio-quentes" (Idem, ibidem).

A partir das variações posicionais dos três grupos de linhas citados, Kandinsky destaca outro tipo de reta: a Linha Semidiagonal ${ }^{8}$ ou Livre. Embora forme um coletivo específico, o artista não a considera um novo grupo, por dois motivos: ela só pode ser formulada mediante sua relação com as demais tipologias e no interior do próprio coletivo; se diferenciam por sua inclinação, ora tendendo para a reta horizontal (frio/azul) ora para a linha vertical (quente/amarelo).

Para concluir seu estudo da linha reta, Kandinsky relata a possibilidade de um processo de combinação entre linhas, incluindo os três grupos e o coletivo de semidiagonais. Para ele, esse processo, denominado de densificação, tem a capacidade de construir superfícies no plano através do entrelaçamento das linhas:

Essa estrela [figura 6] pode se tornar cada vez mais densa, de modo que as intersecções criam um centro mais denso, no qual um ponto se forma e parece crescer. Ele é o eixo em torno do qual as linhas podem girar e, enfim, se confundir - nasce uma nova forma: uma superfície sob a forma definida do círculo (KANDINSKY, 2005, p. 52)
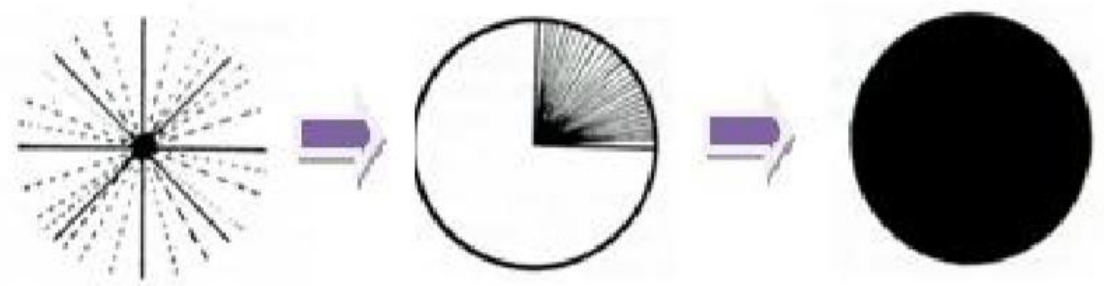

Figura 6: Processo de Densificação por Linhas. Fonte: Kandinsky (2005)

\section{Linhas Retas Quebradas}

Para Kandinsky, há dois casos específicos em que a linha reta sofre atuação, não de uma, mas de duas forças, em sua produção. Ele as denomina de Linhas Quebradas Angulares e Linhas Quebradas Complicadas.

(1) Linhas Quebradas Angulares: compostas por duas partes, resultantes de duas forças cessadas após uma única pressão no ponto de origem. Estabelecem uma relação íntima com o espaço, porque comportam em si a promessa do plano, instituindo, com sua forma, o encontro de duas direções diferentes. A partir da questão angular, Kandinsky considera três categorias esquemáticas para esse tipo de linha:

\footnotetext{
${ }^{8}$ Vale destacar que quando Kandinsky utiliza o prefixo semi, não o remonta como uma parte, mas como um reflexo da mesma.
} 
a) Aguda: a linha com o ângulo de $45^{\circ}$. O uso dessa reta visa à ressonância no observador de caracteres como o acelerado e o hiperativo. Essa linha tende para a cor amarela.

b) Reta: a linha com o ângulo de $90^{\circ}$. Considerada a perfeição entre as linhas angulares, pois divide o plano em quatro partes iguais sem nenhum resto. É a mais fria de todas as retas e consiste numa tendência ao vermelho (equilíbrio amarelo-azul).

c) Obtusa: a linha com ângulo de $135^{\circ}$. Através dela ressoa um sentimento de insatisfação e uma sensação de fraqueza interior, o que se traduz num caráter pesado/desajeitado na produção. Na sua formulação, tende para a cor azul.

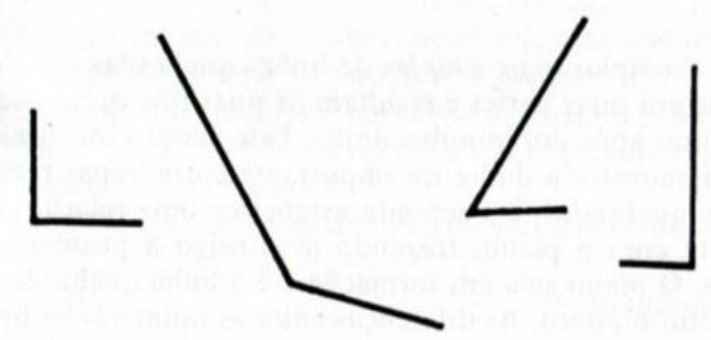

Figura 7: Algumas Linhas Angulares. Fonte: Kandinsky (2005)

Assim como na seção anterior, as variações posicionais das categorias angulares geram outra forma linear: a linha quebrada livre. Na compreensão de Kandinsky (2005), não há uma ressonância ou cor pré-dada para a linha livre, pois ela se constitui conforme sua aproximação com as demais retas quebradas. Ou seja, se está mais próximo do ângulo agudo terá, por exemplo, a tendência interior ao acelerado e hiperativo.

(2) Linhas Quebradas Complicadas: originárias da junção entre linhas angulares com outras retas, sendo que o ponto que as determina sofre várias pressões que emergem de duas forças alternantes. Essas linhas podem ser chamadas de ziguezague, pois são consideradas como linhas retas que sofrem desvios móveis. Essa modificação de direção da linha ocorre por dois tipos de combinação:

a) De ângulos agudos, retos, obtusos ou livres; ou

b) Pelos diferentes comprimentos das seções.

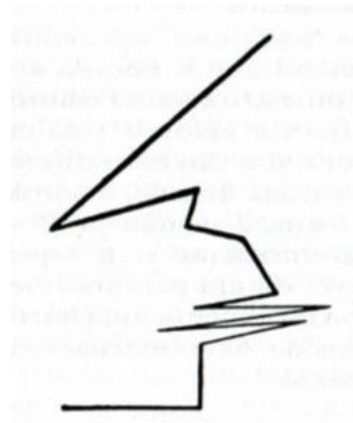

Figura 8: Exemplo de Linha Quebrada Complicada. Fonte: Kandinsky (2005) 


\section{Linhas curvas}

Kandinsky ressalta que "se duas forças exercem sua ação sobre o ponto simultaneamente, de sorte que uma é contínua e preponderante, produz-se uma linha curva" (2005, p. 70). Para ele, as linhas curvas se dividem em dois grupos:

(1) Curva simples: não é nada mais do que uma linha reta que se desvia do seu caminho mediante uma pressão lateral contínua. Pressão que define, igualmente, a acentuação do desvio da curva: quanto mais intensa a pressão, mais fechada sobre si mesma estará à linha.

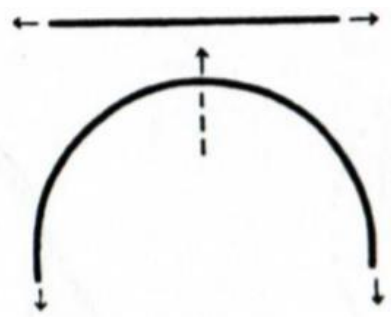

Figura 9: Relação Linha Curva e Linha Reta

Fonte: Kandinsky (2005)

Kandinsky elenca dois casos específicos de linhas curvas simples, usadas, comumente, pelo artista: o arco e o espiral. O primeiro possui uma semelhança intrínseca com o ângulo obtuso, tendendo ao plano e, especialmente, ao círculo. Na pintura abstracionista do artista, o arco assume uma natureza interna passiva e neutra, consistindo de "uma maturidade e uma força consciente de si mesma" (Idem, ibidem). Já no segundo caso, exerce-se sobre a linha um desvio constante e regular, em que a força contínua interna excede a força contínua externa:
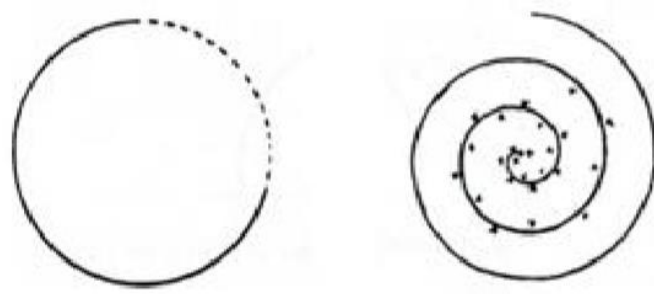

Figura 10: Exemplos de Arco e Espiral

Fonte: Kandinsky (2005)

(2) Linha ondulada: denominada também de curva complicada, compõe-se a partir de três espécies: segmentos de círculo, curvas livres ou diferentes combinações destes. Essas espécies definem todas as possíveis formas de linhas curvas:

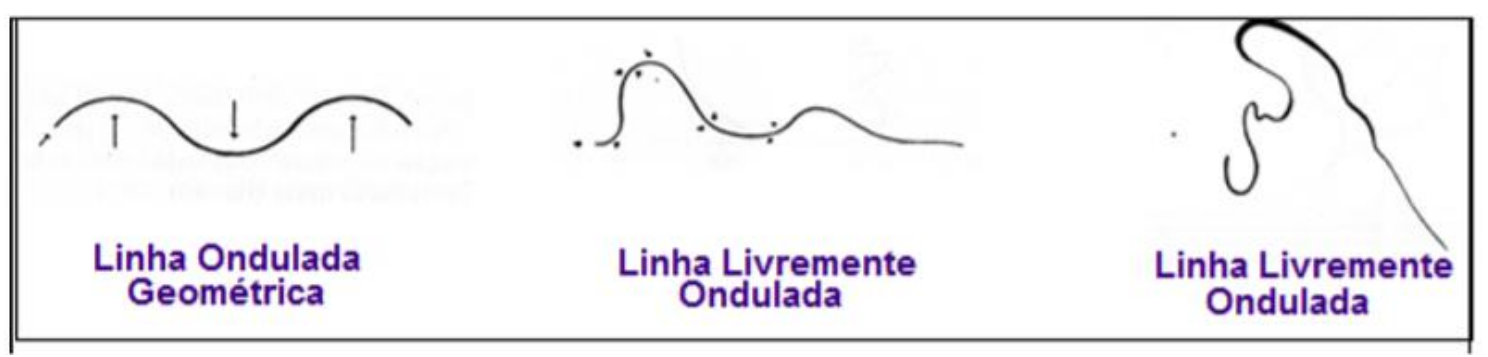

Figura 11: Exemplos de Linha Ondulada. Fonte: Kandinsky (2005) 


\section{Linhas combinadas (Kombinierte)}

A linha combinada surge do uso conjunto das duas tipologias de linhas anteriores, as retas e as curvas. No interior desse grupo, Kandinsky diferencia três modos possíveis de composição:

(1) Linha Combinada Geométrica: composta somente de seções geométricas;

(2) Linha Combinada Mista: composta tanto de seções livres quanto de seções geométricas;

(3) Linha Combinada Livre: composta somente de seções livres.

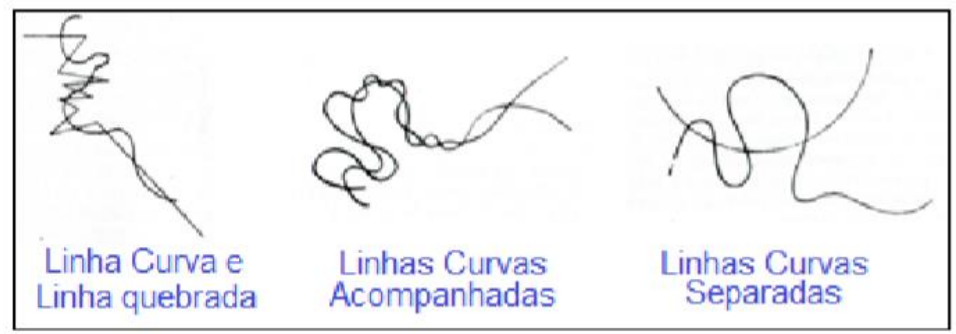

Figura 12: Exemplos de Linhas Combinadas. Fonte: Kandinsky (2005)

\section{Um Plano...}

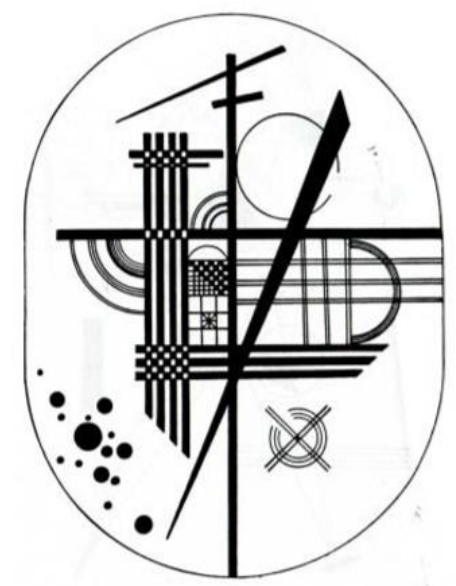

Figura 13: Prancha 24. Fonte: Kandinsky (2005)

Kandinsky define o Plano Original (PO) como a "superfície material destinada a suportar o conteúdo da obra" (2005, p.105). O PO esquemático é composto pela limitação de duas linhas horizontais e duas verticais, o que acarreta, no entendimento do pintor, uma construção autônoma e relacional entre o calmo-frio (horizontal) e o calmo-quente (vertical), exercendo uma influência direta sobre os elementos primários e secundários postos nele.

Além dos anteriores, em sua Teoria da Forma, Kandinsky levanta diversos aspectos do PO que interferem na composição pictórica, entre os quais:

a) Material do plano - o material que compõe o PO produz características diversificadas numa pintura: áspera, lisa, fosco, brilhante,... 
b) Altura do plano - o plano pode ser alto ou baixo. O alto proporciona à obra leveza, maleabilidade e liberdade; o baixo configura densidade, peso e coerção.

c) Direção do plano - o plano pode ser esquerdo ou direito. O esquerdo possui profunda relação com o alto, diferenciando-se apenas pelos graus de presença das qualidades de leveza, maleabilidade e liberdade, sendo menores que no alto. Já o direito tem profunda relação com o baixo, diferenciando-se apenas pela menor presença das qualidades de densidade, peso e coerção.

Mediante os aspectos levantados, Kandinsky considera duas possibilidades para estruturar o PO:

(1) Plano Quadrado: é a forma mais objetiva de um PO, pois traz o equilíbrio pleno entre o quente e o frio. Sua composição dá-se por duas linhas verticais e duas horizontais, todas com o mesmo comprimento:

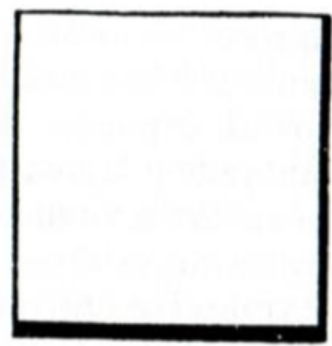

Figura 14: Exemplo de Plano Quadrado. Fonte: Kandinsky (2005)

(2) Outros PO: são figuras que "resultam da predominância dos limites horizontais ou verticais" (2005, p. 128), de tal forma, que prevalecerá o princípio interior da calma-fria ou da calma-quente na estrutura do plano. Há, então, a eliminação da objetividade do quadrado, bem como uma tensão subjetiva no PO por inteiro. A seguir, apresentamos dois exemplos citados pelo artista:

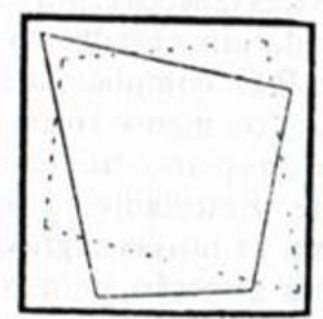

PO Estimulante

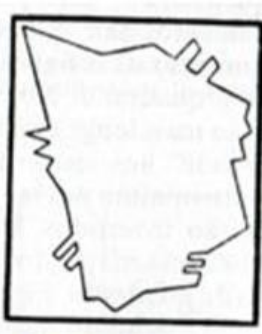

PO Complexo

Figura 15: Exemplos de Outros PO. Fonte: Kandinsky (2005)

\section{Os Elementos e suas ressonâncias interiores}

Nas seções anteriores, descrevemos os elementos prescritos por Kandinsky em sua Teoria da Forma: o ponto, a linha e o plano. Porém, para o artista, uma forma de nada serve se não objetivar uma sonoridade naquele que a observa. Minimamente, já abordamos

\footnotetext{
${ }^{9} \mathrm{O}$ esquerdo é o lado situado à esquerda do observador, quando posicionado de frente para o plano. Logo, o "direto" está à sua direita (KANDINSKY, 2005).
} 
as ressonâncias interiores que tais elementos produzem no sujeito, mas reservamos aqui um pequeno espaço para debater o assunto, tendendo antes para uma síntese do exposto até agora do que para uma inclusão de novas ideias.

Antes de tudo, vale destacar que, embora Kandinsky relacione cada um dos seus elementos a uma sonoridade na alma humana, ele ressalta que uma mesma forma, associada a outras diferentes, refletirá distintas ressonâncias interiores. Por exemplo, uma linha, ainda que tenha sonoridade própria, nunca está sozinha na composição, pois tanto sua forma quanto sua ressonância são condicionadas pelas formas e ressonâncias que a obra completa tem por finalidade.

A seguir, elencamos as ressonâncias interiores dos elementos construídos pelo artista em sua teoria:

(1) O ponto. Gênese da criação humana que ressoa a suspensão momentânea, uma rápida captação da atenção do observador. O ponto é tudo aquilo que pode vir a ser, um devir de movimento, forma e investigação do espaço. Possui uma força espiritual latente, um sopro de vida que almeja relacionamento, ocupando um espaço e tempo fixo no plano do quadro. A introspecção e a permanência são suas características mais efetivas, capazes de atrair o olhar e gerar pequenas pausas concentradas.

(2) A linha. Ressoa o dinamismo, o rompimento da inércia e a investigação do espaço. Quando se movimenta no sentido de dentro para fora, sua ressonância interior busca relacionar-se; quando o sentido é inverso, está à procura de reserva e intimidade. A linha consiste no único elemento da Teoria da Forma capaz de brincar com o equilíbrio da pintura.

Abaixo, retratamos as possíveis ressonâncias para os grupos de linhas, conforme Kandinsky (2005):

\begin{tabular}{|c|c|}
\hline Tipologia de Linha & Ressonância Interior \\
\hline Reta Horizontal & Calma e imobilidade \\
\hline Reta Vertical & Silêncio e estagnação \\
\hline Reta Diagonal & Expressividade e dinamismo \\
\hline Retas Livres & Desequilíbrio \\
\hline Reta Angular Aguda & Ansiedade \\
\hline Reta Angular reta & Precisão \\
\hline Reta Angular obtusa & Temor \\
\hline Retas Quebradas Complicadas & Instabilidade \\
\hline Curva simples & Neutralidade \\
\hline Linhas onduladas & Conforme a predominância da força específica \\
que se encontra em cada linha.
\end{tabular}

Tabela 2: Ressonâncias Interiores das Linhas.

(3) O plano. Abriga o espaço da arte, o lócus de multiplicidade e dinamismo em que a pintura acontece. Tudo é possível no PO: volume ou superficialidade, invisibilidade ou visibilidade, exatidão ou desestabilização. Tais possibilidades surgem pelas infinidades direcionais presentes no espaço: para frente, para traz, lado direito, lado esquerdo, diagonal direta frente e diagonal direta atrás, diagonal esquerda frente e diagonal esquerda atrás. Assim, a ressonância do plano remete diretamente à variedade de seus contornos e dos elementos presentes na obra à qual pertence. 


\section{Considerações finais}

Ao retornarmos ao objetivo deste trabalho, analisar a relação de Kandinsky, em sua Teoria da Forma, com o pensamento geométrico para a construção da arte abstracionista, é possível considerar que as obras do artista em questão ressoam muito dos elementos históricos e culturais do início do século XX, tanto os presentes na ciência quanto no ideário da sociedade..

Nesse sentido, mediante a abordagem realizada nesse trabalho, torna-se possível criar espaços para o debate dos impactos da organização matemática das imagens na construção de impressões sentimentais, bem como buscar formas de produzir relações interdisciplinares entre Arte e Matemática pelo viés da história. Característica que, de certa forma, possibilita propor a inclusão de olhares diversos sobre os mesmos elementos, como o fez Kandinsky sobre o ponto, a linha e o plano.

Para concluir, considero necessário ressaltar a intenção transversal que se propõe no artigo, uma vez que o autor tenta amenizar as práticas hierárquicas entre campos do saber. Isto é, a necessidade de criarmos práticas histórico-culturais que não associem a valorização da matemática como sinônimo de redução de relevância de outras áreas - Artes Plásticas, Filosofia, Ciências Geográficas, etc. Além disso, ressalto a potência que este olhar possibilita para os aspectos culturais envolvidos nos pressupostos das geometrias não-euclidianas do final do século XIX (Gauss (1777-1855), Bolyai (1802-1860), Lobatschevisky (1792=1856) e Riemann (1826-1866)), de modo a criar espaços para debates didáticos em sala de aula.

\section{Referências}

BARBOSA, E. Espaço-Tempo e Poder-Saber: uma nova epistéme? (Foucault e Bachelard). Tempo Social: Rev. Sociol. USP, S. Paulo, 7(12): 111-120, outubro de 1995.

CASTRO, E. Vocabulário de Foucault: um percurso pelos seus temas, conceitos e autores. Belo Horizonte: Autêntica, 2009.

CRARY, J. Técnicas do Observador: visão e modernidade no século XIX. Rio de Janeiro: Contraponto, 2012.

FORTUNA, M. Arte abstrata: uma comunicação peculiar; os audiovisuais a serviço do abstracionismo. In: Anais do Intercom - Congresso Brasileiro de Ciências da Comunicação. Brasília: UnB, 2006.

KANDINSKY, W. Ponto e Linha sobre o Plano. Tradução de José Eduardo Rodil. São Paulo: Martins Fontes, 2005.

KANDINSKY, W. Olhar no Passado. Tradução de Antônio de Pádua Danesi. São Paulo: Martins Fontes, 1991a.

KANDINSKY, W. Der Blaue Reiter. Tradução de Antônio de Pádua Danesi. São Paulo: Martins Fontes, 1991b.

MENON JR, W. R. Espiritual na Arte e Magia. A Noção de Gênio na obra de Kandinsky. Dois Pontos, v.11, n. 1, 2014

SOUSA SANTOS, B. de. Um Discurso sobre as Ciências. Porto: afrontamento, 1996. 
SCHMIDT, C. O artista e a leitura científica proposta de uma metodologia baseada na analise dos livros científicos da biblioteca pessoal de Vassili Kandinsky. Cadernos de posgraduacao: Instituto de Artes/UNICAMP, 1999, ano 3, volume 3, n.2.

SERS, M. Prefácio. In: KANDINSKY, Wassily. Ponto e Linha sobre o Plano. Tradução de José Eduardo Rodil. São Paulo: Martins Fontes, 2005.

SILVA, V. C. A Filosofia da Ciência da Mecânica Quântica e a Construção da Ontologia Materialista. Cadernos do PET Filosofia - v. 1, n. 2, p. 30-43, 2010. 